\title{
High dietary daidzein intake lowers cholesterol levels among post-menopausal women
}

\author{
Elly Herwana ${ }^{*}$, Pusparini* ${ }^{* *}$, and Audria Graciela***
}

\begin{abstract}
\section{BACKGROUND}

Menopause is associated with changes in metabolic profile. Although hormone replacement therapy (HRT) has been shown to have beneficial effects on lipid metabolism, its adverse effects have indicated a need for alternative estrogen-based treatments. Several investigations have evaluated the effects of isoflavones on serum lipid levels in postmenopausal women, but the results were ambiguous. The objective of this study was to determine the relationship of dietary daidzein, genistein, and glycitein levels with lipid profile in postmenopausal women.
\end{abstract}

\section{METHODS}

A cross-sectional study was conducted involving 186 post-menopausal women. A food recall questionnaire was used to measure dietary genistein, daidzein, and glycitein levels. Serum total cholesterol (TC), low density lipoprotein (LDL) cholesterol, high density lipoprotein (HDL) cholesterol, and triacylglycerol (TAG) were measured using the enzymatic colorimetric method. Simple and multivariate linear regression were used to analyze the data.

\section{RESULTS}

Genistein intake was significantly associated with $\mathrm{TC}(\beta=145.48, \mathrm{p}=0.023)$ and HDL cholesterol levels $(\beta=48.80, p=0.032)$. Daidzein intake was significantly associated with $\mathrm{TC}(\beta=-204.60, \mathrm{p}=0.003)$, LDL cholesterol $(\beta=-$ $160.81, p=0.014)$ and HDL cholesterol levels $(\beta=-67.118, p=0.032)$. Glycitein was not significantly associated with $\mathrm{TC}(\beta=232.78 ; \mathrm{p}=0.133)$, HDL $(\beta=43.59 ; p=0.428)$, and $\operatorname{LDL}(\beta=235.84 ; p=0.116)$. Dietary daidzein had a more lowering effect on TC $($ Beta $=-2.80)$ and HDL cholesterol $($ Beta $=-2.67)$ than had genistein on TC $(B e t a=2.66)$ and HDL cholesterol (Beta=2.03).

\section{CONCLUSIONS}

High dietary daidzein level has a significant lowering effect on TC, LDL cholesterol and HDL cholesterol in post-menopausal women. Our study supports the advice given to the public to increase soy isoflavone intake in post-menopausal women.

Keywords : Daidzein, genistein, glycitein, serum lipid, postmenopausal women
*Department of Pharmacology and Pharmacy, Faculty of Medicine,

Trisakti University

**Department of Clinical Pathology,

Faculty of Medicine, Trisakti

University

*** Department of Medical Checkup, Mintoharjo Hospital

\section{Correspondence:}

Dr. dr. Elly Herwana, M.Biomed Department of Pharmacology and Pharmacy, Faculty of Medicine,

Trisakti University

J1. Kiyai Tapa, Grogol, (Kampus B), Jakarta 11440

Phone : $+62-5672731$ ext.2801

Email: elly.herwana@trisakti.ac.id

ORCID: 0000-0003-1814-1189

Date of first submission, March 3, 2019

Date of final revised submission, April 8, 2020

Date of acceptance, April 9, 2020

This open access article is distributed under a Creative Commons AttributionNon Commercial-Share Alike 4.0 International License

Cite this article as: Herwana E, Pusparini, Graciela I. High dietary daidzein intake lowers cholesterol levels among post-menopausal women. Univ Med 2020;39:47-54. doi: 10.18051/UnivMed.2020.v39.47-54 


\section{INTRODUCTION}

Menopause is a physiological condition in the female life cycle that is marked by the cessation of menstruation and the end of reproductive capacity. The condition of menopause is associated with decreased ovarian function, thereby causing a reduction in the circulatory estrogen level. The lower mortality from cardiovascular disease (CVD) in premenopausal women as compared to males is associated with the protective effects of estrogen and progesterone. ${ }^{(1-3)}$ Estrogen demonstrates cardioprotective effects through maintaining high high-density lipoprotein (HDL), high low-density lipoprotein (LDL) and low triacylglycerol (TAG) levels. The decreased estrogen level increases dyslipidemia and thus the risk of CVD. ${ }^{(3-5)}$ Increasing age is associated with increased CVD risk. The differences between the premenopausal, perimenopausal, and postmenopausal phases lie in the increases in body mass index (BMI), systolic blood pressure, diastolic blood pressure, and LDL and TAG levels. The increased LDL and TAG levels are demonstrable after the age of 45 years and increase sharply in the perimenopausal and postmenopausal phases. ${ }^{(6)}$

Hormone replacement therapy for estrogen, which had been expected to be able to return the cardioprotective effects of estrogen, turned out not to show the effects in question. The administration of exogenous estrogen is associated with increased risk of venous thrombosis, resulting in myocardial infarction, stroke, and peripheral arterial disease. The possibility of estrogen being associated with prothrombotic effects is still a subject of controversy and is as yet incompletely understood. ${ }^{(7)}$ A study conducted by the Women's Health Initiative (WHI) that evaluated and compared the effects of conjugated equine estrogens (CEE), singly or concurrently with medroxyprogesterone acetate (MDE), reported that there was an increase in the risk of CVD, stroke, and breast malignancies in both groups. ${ }^{(8,9)}$
The difference in cardiovascular disease prevalence between Asian and Caucasian women had led to opinions on the difference in dietary patterns. Isoflavones that are present in high levels in soybean-derived foods, are consumed in higher amounts by Asian than by Caucasian women. ${ }^{(10)}$ Soybeans contain inactive glycosides of isoflavones. The isoflavones in the gut are hydrolyzed by intestinal bacterial $\beta$-glucosidases to yield bioactive aglycones that can be detected in the blood. The isoflavone derivatives with a molecular structure similar to that of estrogen, are believed to act as phytoestrogens. Genistein, daidzein, and glycitein that are aglycones of soy isoflavone, have a molecular structure similar to that of 17ß-estradiol and show estrogenic effects. The phenolic ring group in soy phytoestrogenic isoflavones is the binding site for estrogen receptors, which comprise two types, namely estrogen- $\alpha(E R \alpha)$ and estrogen- $\beta$ (ER $\beta)$ receptors. Isoflavones as partial agonists show an affinity to the estrogen receptors, particularly to ER $\beta .^{(11,12)}$ Another mechanism of the biological effects of isoflavones is through activation of peroxisome proliferator activated receptors (PPAR $\alpha$ and PPAR $\gamma$ ), resulting in decreased hepatic lipid synthesis, bile acid synthesis, and cholesterol absorption. ${ }^{(13,14)}$

Many studies have been conducted on the effects of isoflavones on lipid profile, but the results are still inconsistent. One study found that phytoestrogens derived from both soy and red clover have a positive metabolic effect on serum lipids of postmenopausal women. Both soy and red clover supplements were found to have an almost equal impact on serum lipid levels. ${ }^{(15)} \mathrm{A}$ meta-analysis performed by Tokede et al. ${ }^{(16)}$ found that soy protein is beneficial for dyslipidemia that is marked by decreased total cholesterol, LDL cholesterol, and TAG, and increased HDL concentrations. The effects are stronger on subjects with hypercholesterolemia. Whole soy foods are more beneficial than soy supplements, and isoflavone supplements are not beneficial for the lipid profile. Differing results were shown in a study on isoflavone supplementation at $60 \mathrm{mg}$ / 
day for three months, in which the supplement did not cause changes in LDL cholesterol levels of postmenopausal women. ${ }^{(17)}$

The still inconclusive results of previous studies need to be investigated further. Therefore the present study aimed to determine the relationship between dietary intakes of isoflavone derivatives and lipid profile in postmenopausal women.

\section{METHODS}

\section{Design of the study}

This was a cross-sectional study conducted in the District Health Center, Mampang Prapatan, South Jakarta, from January 2010 until February 2011.

\section{Study subjects}

Females aged 47-60 years meeting the criterion of natural menopause (cessation of menstruation for 1-10 years and not resulting from hysterectomy or medications) were recruited as study subjects. Females with a history of malignancies of the breast or reproductive organs, renal failure, diabetes mellitus, heart disease, hyperthyroidism, post stroke, currently on estrogen replacement therapy, or consuming isoflavone-containing supplements, were excluded from the study.

A preliminary study by one of the investigators $(\mathrm{EH})$ showed a correlation between daidzein intake and TC level of -0.25 (data not shown). On the basis of the preliminary study results, with $\alpha=0.05$ and $\beta=0.1$ and a drop-out of $15 \%$, the required sample size was 186 .

\section{Determination of isoflavone intake}

Isoflavone intake was calculated from food recall, especially for isoflavone-containing foods. The subjects were asked to record the foods they consumed during one whole day. Food recall was performed twice, with an interval of one week. Food recall was done using interviews to confirm the food record and using food models as aids in recall. The evaluation of food recall was aimed at determining soy isoflavone intake in the foods consumed by the subjects.

\section{Anthropometric measurements}

Weight was measured in $\mathrm{kg}$ using portable scales with an accuracy of $0.1 \mathrm{~kg}$. Height was measured in $\mathrm{cm}$ using a portable microtoise with accuracy of $0.1 \mathrm{~cm}$. Body mass index (BMI) was determined from calculation of weight in $\mathrm{kg}$ divided by height in $\mathrm{m}^{2}$. The BMI values were categorized using the criteria determined by the Department of Health of the Republic of Indonesia, namely: underweight $\left(<18 \mathrm{~kg} / \mathrm{m}^{2}\right)$, normal weight (18-25 kg/m²), overweight (25$\left.27 \mathrm{~kg} / \mathrm{m}^{2}\right)$, and obese $\left(>27 \mathrm{~kg} / \mathrm{m}^{2}\right) \cdot{ }^{(18)}$

\section{Laboratory analysis}

Laboratory examinations were initiated with the collection of $10 \mathrm{ml}$ venous blood samples from the subjects after a fast of 10-12 hours before the collection. For the determination of the blood lipid profile the total cholesterol, LDL cholesterol, HDL cholesterol, and TAG levels were measured by means of an enzymatic colorimetric method, using the Roche Cobas c111 analyzer.

\section{Statistical analysis}

Simple linear regression and multivariate regression was used to evaluate the relationship between variables. The level of significance used was 0.05 .

\section{Ethical clearance}

All subjects agreed to sign informed consent and the proposal for this study obtained approval from the Ethics Commission, Faculty of Medicine, Trisakti University, under no. 140/ KER/FK/IX/2009.

\section{RESULTS}

A total of 186 postmenopausal women meeting the inclusion and exclusion criteria participated in this study. Mean age of the subjects was $53.59 \pm 3.54$ years. For the 
Table 1. Distribution of socio-demographic characteristics and other important variables in postmenopausal women $(\mathrm{n}=186)$

\begin{tabular}{|c|c|}
\hline \multicolumn{2}{|l|}{ Characteristic } \\
\hline Age $\left(\right.$ years) ${ }^{\mathrm{a})}$ & $53.59 \pm 3.54$ \\
\hline \multicolumn{2}{|l|}{ Educational level $\left.{ }^{b}\right)$} \\
\hline Low & $166(89.20 \%)$ \\
\hline Middle & $20(10.80 \%)$ \\
\hline \multicolumn{2}{|l|}{ Employment ${ }^{\mathrm{b})}$} \\
\hline Employed & $59(31.70 \%)$ \\
\hline Unemployed & $127(68.30 \%)$ \\
\hline Duration of menopause (years) ${ }^{a}$ & $4.40 \pm 2.23$ \\
\hline $\operatorname{BMI}\left(\mathrm{kg} / \mathrm{m}^{2}\right)^{\mathrm{a})}$ & $26.82 \pm 4.67$ \\
\hline \multicolumn{2}{|l|}{ Blood pressure ${ }^{a)}$} \\
\hline Systolic & $124.87 \pm 20.44$ \\
\hline Diastolic & $78.63 \pm 11.93$ \\
\hline \multicolumn{2}{|l|}{ Isoflavone intake $(\mathrm{g} / \text { day })^{\mathrm{a})}$} \\
\hline Genistein & $0.11 \pm 0.12$ \\
\hline Daidzein & $0.19 \pm 0.14$ \\
\hline Glycitein & $0.04 \pm 0.04$ \\
\hline \multicolumn{2}{|l|}{ Lipid profile $(\mathrm{mg} / \mathrm{dL})^{\mathrm{a})}$} \\
\hline Total cholesterol & $207.18 \pm 35.62$ \\
\hline LDL cholesterol & $129.87 \pm 33.51$ \\
\hline HDL cholesterol & $56.91 \pm 12.16$ \\
\hline Triglycerides & $117.42 \pm 68.49$ \\
\hline
\end{tabular}

a)Values are mean \pm standard deviation; ${ }^{\text {b) }}$ number of subjects (\%)

isoflavone intakes determined from total intake of isoflavone derivatives per day, it was found that the highest intake was that of daidzein. The lipid profile showed that total cholesterol level was slightly above normal, while LDL, HDL and TAG levels were within normal limits (Table 1).

The results of simple linear regression analysis showed that total cholesterol level was significantly associated with genistein level and BMI $(\beta=145.48, p=0.023 ; \beta=2.03, p=0.000$, respectively) and inversely and significantly associated with daidzein level $(\beta=-204.06$, $\mathrm{p}=0.003)$. LDL cholesterol was significantly associated with BMI and inversely associated with daidzein level $(\beta=1.90, p=0.000 ; \beta=-160.81$, $\mathrm{p}=0.014)$. HDL cholesterol was significantly associated with genistein level and inversely associated with daidzein level and BMI $(\beta=48.80$, $p=0.03 ; \beta=-67.11 ; p=0.006 ; \beta=-0.43, p=0.021$, respectively). TAG level was significantly associated with BMI and inversely associated with employment $(\beta=4.011, p=0.000 ; \beta=21.98$, $\mathrm{p}=0.033)$ (Table 2).

The risk factors that were significantly associated with cholesterol level were entered into the multiple linear regression model.

The results of the multiple regression analysis of the relationship between lipid profile and several risk factor variables showed that total cholesterol was significantly associated with genistein level and BMI $(\beta=167.83, p=0.008 ; \beta=$ $2.06, p=0.000$, respectively) and inversely and significantly associated with employment and daidzein level $(\beta=-11.18, p=0.036 ; \beta=-148.45$, $\mathrm{p}=0.006$, respectively). LDL cholesterol was significantly associated with BMI $(\beta=1,83$, $\mathrm{p}=0,000)$. HDL cholesterol HDL was significantly associated with genistein level $(\beta=44.99, p=0,044)$ and inversely associated with daidzein and BMI $(\beta=-49.741, p=0.008 ; \beta=-0.43, p=0,02$, respectively). TAG level was significantly associated with BMI $(\beta=4.28, p=0.000)$ and inversely associated with employment $(\beta=-24.41$, $\mathrm{p}=0.018)$ (Table 3 ).

Genistein intake was significantly associated with increases in cholesterol and HDL cholesterol levels. Daidzein intake was significantly associated with decreased total cholesterol, LDL cholesterol, and HDL cholesterol level.

\section{DISCUSSION}

The results of this study showed that higher daidzein intakes were associated with total lower cholesterol, LDL cholesterol, and HDL cholesterol levels. Genistein intake was associated with higher total cholesterol and HDL cholesterol levels. The results of this study differ from those of a meta-analytic study by Tokede et al. ${ }^{(16)}$ who report that the effects of soy products are of benefit in significantly lowering the total cholesterol, LDL cholesterol, and TAG level by $2 \%, 3 \%$, and $4 \%$, respectively, and increasing the HDL level by $3 \%$, the effects being more pronounced in subjects with hypercholesterolemia. Whole soy food is more 
Table 2. Relationship of various important variables with cholesterol in postmenopausal women

\begin{tabular}{|c|c|c|}
\hline Characteristic $(n=186)$ & $\boldsymbol{\beta}$ & p value \\
\hline \multicolumn{3}{|l|}{ Total cholesterol (mg/dL) } \\
\hline Age (years) & 1.50 & 0.057 \\
\hline Employment & -11.22 & $0.035 *$ \\
\hline Education & 11.08 & 0.171 \\
\hline Genistein (g/day) & 145.48 & $0.023 *$ \\
\hline Daidzein (g/day) & -204.06 & $0.003 *$ \\
\hline Glycitein (g/day) & 232.78 & 0.133 \\
\hline Duration of menopause (years) & -0.52 & 0.673 \\
\hline BMI $\left(\mathrm{kg} / \mathrm{m}^{2}\right)$ & 2.03 & $0.000 *$ \\
\hline Systolic BP (mmHg) & 0.06 & 0.760 \\
\hline Diastolic BP (mmHg) & 0.07 & 0.823 \\
\hline \multicolumn{3}{|l|}{ HDL cholesterol (mg/dL) } \\
\hline Age (years) & 0.15 & 0.580 \\
\hline Employment & 0.59 & 0.751 \\
\hline Education & 3.32 & 0.249 \\
\hline Genistein (g/day) & 48.80 & $0.032 *$ \\
\hline Daidzein (g/day) & -67.11 & $0.006 *$ \\
\hline Glycitein (g/day) & 43.59 & 0.428 \\
\hline Duration of menopause (years) & -0.55 & 0.211 \\
\hline $\mathrm{BMI}\left(\mathrm{kg} / \mathrm{m}^{2}\right)$ & -0.43 & $0.021 *$ \\
\hline Systolic BP (mmHg) & 0.09 & 0.177 \\
\hline Diastolic BP (mmHg) & -0.20 & 0.098 \\
\hline \multicolumn{3}{|l|}{ LDL cholesterol } \\
\hline Age (years) & 0.70 & 0.354 \\
\hline Employment & -7.17 & 0.162 \\
\hline Education & 10.70 & 0.172 \\
\hline Genistein (g/day) & 104.02 & 0.091 \\
\hline Daidzein (g/day) & -160.81 & $0.014 *$ \\
\hline Glycitein (g/day) & 235.84 & 0.116 \\
\hline Duration of menopause (years) & 0.05 & 0.966 \\
\hline BMI $\left(\mathrm{kg} / \mathrm{m}^{2}\right)$ & 1.90 & $0.000 *$ \\
\hline Systolic BP (mmHg) & -0.07 & 0.696 \\
\hline Diastolic BP (mmHg) & 0.17 & 0.603 \\
\hline \multicolumn{3}{|l|}{ Triacylglycerol } \\
\hline Age (years) & 1.99 & 0.193 \\
\hline Employment & -21.98 & $0.033 *$ \\
\hline Education & -10.41 & 0.507 \\
\hline Genistein (g/day) & 2.14 & 0.986 \\
\hline Daidzein (g/day) & 91.91 & 0.482 \\
\hline Glycitein (g/day) & -227.85 & 0.448 \\
\hline Duration of menopause (years) & 0.53 & 0.825 \\
\hline BMI $\left(\mathrm{kg} / \mathrm{m}^{2}\right)$ & 4.01 & $0.000 *$ \\
\hline Systolic BP (mmHg) & 0.24 & 0.534 \\
\hline Diastolic BP (mmHg) & 0.49 & 0.470 \\
\hline
\end{tabular}

$\mathrm{p}$ values calculated by simple linear regression; "significant; $\mathrm{BP}=$ blood pressure; $\mathrm{HDL}=$ high density lipoprotein; $\mathrm{LDL}=$ low density lipoprotein; BMI = body mass index; Educational level: low = no schooling, elementary school, and junior high school; middle $=$ senior high school

beneficial than isoflavone supplementation and the effects of soy protein are stronger in the postprandial than the fasting state. ${ }^{(19)}$ The study of Jassi et al. ${ }^{(17)}$ compared the effects of supplementation of $30 \mathrm{~g}$ /day soy protein powder (containing $60 \mathrm{mg}$ isoflavone) and $60 \mathrm{mg} /$ day soy isoflavone tablets on the lipid profile, with $30 \mathrm{~g} /$ day of casein as control. The supplementation was administered for 12 weeks and was evaluated at 4 and 12 weeks. The results 
Table 3. Multiple linear regression analysis of the relationship of various risk factor variables with cholesterol level in postmenopausal women

\begin{tabular}{lccc}
\hline Risk factor & B & Beta & p value \\
\hline Total cholesterol (mg/dL) & & & \\
Employment & -11.18 & -2.11 & $0.036^{*}$ \\
Genistein (g/day) & 167.83 & 2.66 & $0.008^{*}$ \\
Daidzein $(\mathrm{g} / \mathrm{day})$ & -148.45 & -2.80 & $0.006^{*}$ \\
BMI $\left(\mathrm{kg} / \mathrm{m}^{2}\right)$ & 2.00 & 3.79 & $0.000^{*}$ \\
HDL cholesterol (mg/dL) & & & \\
Genistein $(\mathrm{g} / \mathrm{day})$ & 44.99 & 2.03 & $0.044^{*}$ \\
Daidzein $(\mathrm{g} / \mathrm{day})$ & -49.74 & -2.67 & $0.008^{*}$ \\
BMI $\left(\mathrm{kg} / \mathrm{m}^{2}\right)$ & -0.43 & -2.33 & $0.020^{*}$ \\
LDL cholesterol (mg/dL) & & -0.03 & 0.672 \\
Daidzein $(\mathrm{g} / \mathrm{day})$ & -6.98 & 0.25 & $0.000^{*}$ \\
BMI $\left(\mathrm{kg} / \mathrm{m}^{2}\right)$ & 1.83 & & \\
Triacylglycerol (mg/dL) & & -0.16 & $0.018^{*}$ \\
Employment & -24.41 & 0.29 & $0.000^{*}$ \\
BMI $\left(\mathrm{kg} / \mathrm{m}^{2}\right)$ & 4.28 &
\end{tabular}

p values calculated by multiple regression; "significant; $\mathrm{HDL}=$ high density lipoprotein; $\mathrm{LDL}=$ low density lipoprotein; $\mathrm{BMI}=$ body mass index

of this study showed that in the group on soy protein there was a significant reduction in total cholesterol, TAG, and LDL cholesterol levels, accompanied by increased HDL cholesterol, whereas soy isoflavone supplementation was only significant in reducing TAG. The results of another study found that supplementation of 100 $\mathrm{mg}$ isoflavone for 6 months significantly decreased LDL cholesterol level, but the decrease became non-significant after 12 months. ${ }^{(20)}$

The isoflavones contained in soy-derived foods comprise inactive glucosides that subsequently undergo hydrolysis by intestinal bacterial $\beta$-glucosidases into the bioactive aglycones genistein, daidzein, and glycitein. The isoflavone intake in the present study, as determined by food recall, showed mean \pm SD values for genistein, daidzein, and glycitein of 0.11 $\pm 0.12 \mathrm{~g}, 0.19 \pm 0.14 \mathrm{~g}$, and $0.04 \pm 0.05 \mathrm{~g}$, respectively. Mean isoflavone intake in the present study was found to be higher than mean isoflavone intake in Asian populations (Japan, China, Korea) that vary from 17.7 to $47.2 \mathrm{mg} /$ day, whereas the isoflavone intake in Caucasian populations are extremely low, namely $<2 \mathrm{mg} /$ day. ${ }^{(10)}$ The Indonesian communities consume great amounts of soy foods, particularly those that are processed into tempeh, tofu, soy milk, and kecap (ketchup). Ethnic differences may affect the bioavailability and pharmacokinetics of isoflavone. Individual capacities in metabolizing the inactive glucosides into the bioactive aglycones genistein, daidzein, and glycitein depend on the hydrolyzing capacities of intestinal bacterial $\beta$-glucosidases. Daidzein may be metabolized into dihydrodaidzein, and subsequently into equol and $\mathrm{O}$ desmethylangolensin (O-DMA). Equol demonstrates a potentially higher effect than daidzein. Only the aglycones genistein, daidzein, glycitein, equol, and O-DMA can enter the circulation and reach the cells. There are interindividual differences in the capacity to metabolize daidzein into equol and this plays a role in the variability of the inter-individual effects of isoflavone, so that the individuals in question may be distinguished into equol producers and nonequol producers. ${ }^{(11)}$ There are differences in the proportions of equol producers between the Asian and Caucasian populations. One study also reported that isoflavone intake may increase the individual capacity to become equol producers. (21) There is the possibility that the inconsistent results of the studies on the effects of isoflavones on lipid profile were associated with interindividual pharmacokinetic variability. 
Meanwhile Chilibeck et al. ${ }^{(22)}$ reported that isoflavone supplementation reduced LDL cholesterol level, but showed no effects on the levels of the other lipids. The isoflavone effects on the risk of cardiovascular disease are still controversial. The European Food Safety Authority has evaluated the effects of isoflavones on the risk of cardiovascular disease, with a focus on the effects on lipid profile. ${ }^{(23)}$ Several previous studies have investigated the important clinical effects of isoflavones on the decreases in total cholesterol, LDL cholesterol, and TAG levels and on the increase in HDL cholesterol levels. These studies that were reported in the last ten years failed to demonstrate that isoflavones exert significant clinical effects, and failed to find the active isoflavone compounds that play a role in lipid metabolism. Intake of soy protein as a nutrient may increase protein intake and reduce carbohydrate and fat intakes, so showing a better effect on lipid profile. The direct benefit of soy protein or isoflavones in cardiovascular health is minimally the best. ${ }^{(24)}$ In spite of this, there are still many studies and meta-analyses that have found significant effects of soy protein in reducing LDL cholesterol and TAG levels by $4-6 \%$ and $5 \%$, respectively, and in increasing HDL cholesterol by 1\%-3\%. Although apparently the effects are not large, they are still relevant for the clinical effects in the population, because epidemiological and interventional data suggest that each $1 \%$ reduction in LDL cholesterol is associated with a $1-2 \%$ reduction in cardiovascular events and that each $2 \%-3 \%$ increase in HDL cholesterol is associated with a $2 \%-4 \%$ reduction in cardiovascular events. ${ }^{(24)}$

The present study has several limitations. Firstly, the cross-sectional study design cannot show any causal relationship. Secondly, the measurement of isoflavone intake using food recall depends on the subjects' memory of the types and amounts of soy-containing foods consumed, and in addition the food processing method was not analyzed. Further studies of prospective design are necessary to confirm our study results.

\section{CONCLUSIONS}

High daidzein intake is associated with low total cholesterol, LDL cholesterol, and HDL cholesterol levels. Genistein intake is associated with high total cholesterol and HDL cholesterol levels. Phytoestrogen intake has no side-effects, so the dietary approach could be considered safe.

\section{CONFLICT OF INTEREST}

The investigators did not have conflicts of interest for the results of this study.

\section{ACKNOWLEDGEMENT}

We are grateful to all postmenopausal women who participated in this study, to the enumerators who assisted in this study and to the Faculty of Medicine, Trisakti University, for the funding of this study.

\section{CONTRIBUTORS}

EH contributed to writing the original draft. $\mathrm{EH}$ and $\mathrm{P}$ contributed to review and editing. AG contributed to data collection and analysis. All authors have read and approved the final manuscript.

\section{REFERENCES}

1. Ueda K, Adachi Y, Fukuma N, Takimoto E. Regulatory actions of estrogen receptor signaling in the cardiovascular system. Front Endocrinol 2020;10. Article 10:909. Doi: 10.3389/ fendo.2019.00909.

2. Newson L. Menopause and cardiovascular disease. Post Reprod Health 2018;24:44-9. Doi: 10.1177/2053369117749675.

3. Pardhe BD, Ghimire S, Shakya J, et al. Elevated cardiovascular risk among postmenopausal women: a community based case control study from Nepal. Biochem Res Int 2017. Article ID 3824903,5 pages. Doi: $10.1155 / 2017 / 3824903$. 
4. Zou H, Zhang C, Ni J, Han X. Prevalence of cardiovascular risk factors in non- menopausal and postmenopausal inpatients with type 2 diabetes mellitus in China. BMC Endocr Disord 2019;92:98, 9 pages. Doi: 10.1186/s12902-019-04277.

5. Zou Y, Wang D, Yang X, et al. Effect of menopausal status on carotid intima-media thickness and the presence of carotid plaque in Chinese women generation population. Scientific Reports 2015;5:8076, 5 pages. Doi: 10.1038/ srep08076.

6. de Kat AC, Dam V, Onland-Moret NC, Eijkmans MJC, Broekmans FJM, van der Schouw YT. Unraveling the associations of age and menopause with cardiovascular risk factors in a large population-based study. BMC Medicine 2017;15:2, 11 pages. Doi: 10.1186/s12916-016-07628.

7. Lorga A, Cunningham CM, Moazeni S, Ruffenach G, Umar S, Eghbali M. The protective role of estrogen and estrogen receptors in cardiovascular disease and the controversial use of estrogen therapy. Biol Sex Difference 2017;8:33, 16 pages. Doi: 10.1186/s13293-017-0152-8.

8. Mansson JE, Chlebowski RT, Stefanick ML, et al. The Woman's Health Initiative hormone therapy trials: update and overview of health outcomes during the intervention and post-stopping phases. JAMA 2013;310:1353-68. Doi: 10.1001/ jama.2013.278040.

9. Roehm E. A reappraisal of Women's Health Initiative Estrogen-Alone trial: Long term outcomes in women 50-59 years of age. Obstet Gynecol Int 2015, Article ID 713295, 10 pages. Doi: $10.1155 / 2015 / 713295$.

10. Vergne S, Sauvant P, Lamothe V, et al. Influence of ethnic origin (Asian v. Caucasian) and background diet on the bioavailability of dietary isoflavones. Br J Nutr 2009;102:1642-53. Doi: 10.1017/S0007114509990833.

11. Pabrich M, Materska M. Biological effect of soy isoflavones in the prevention of civilization diseases. Nutrients 2019;1,1660, 13 pages. Doi:10.3390/nu11071660.

12. Wang Q, Ge X, Tian X, Zhang Y, Zhang P. Soy isoflavone: the multipurpose phytochemical. Biomedical Reports 2013:1;697-701. Doi: 10.3892/ br.2013.129.

13. Ramdath DD, Padhi EMT, Sarfaraz S, Renwick S, Duncan AM. Beyond the cholesterol-lowering effect of soy protein: A review of the effects of dietary soy and its constituents on risk factors for cardiovascular disease. Nutrients 2017;9:324, 25 pages. doi:103390/nu9040324.
14. Patel RP, Barnes S. Isoflavones and PPAR signaling: a critical target in cardiovascular, metastatic, and metabolic disease. PPAR Res 2010. Article ID 153252, 10 pages. doi:10.1155/ 2010/153252.

15. Terzic M, Micic J, Dotlic J, Maricic S, Mihailovic T, Knezevic N. Impact of phytoestrogens on serum lipids in postmenopausal women. Geburtshilfe Frauenheilkd 2012;72:527-31. doi: 10.1055/s-0031-1298624.

16. Tokede OA, Onabanjo TA, Yansane A, Gaziano JM, Djoussé L. Soya products and serum lipid: a meta-analysis of randomized controlled trials. $\mathrm{Br}$ J Nutr 2015;114:831-4. Doi: 10.1017/ S0007114515002603.

17. Jassi HK, Jain A, Arora S, Chitra R. Effect of soy proteins vs soy isoflavones on lipid profile in postmenopausal women. Indian J Clin Biochem 2010;25:201-7.

18. Kemenetrian Kesehatan. Status gizi dewasa menurut indeks massa tubuh: Riset kesehatan dasar (Riskesdas) 2010. Jakarta : Badan Penelitian and Pengembangan Kesehatan, Kementerian Kesehatan Republik Indonesia;2013.

19. Santo AS, Santo AM, Browne RW, et al. Postprandial lipemia detects the effect of soy protein on cardiovascular disease risk compared with the fasting lipid profile. Lipids 2010;45:112738. Doi: 10.1007/s11745-010-3487-z

20. Yenny, Pusparini. Isoflavone supplementation reduces low-density lipoprotein cholesterol levels in postmenopausal women. Univ Med 2013;32:197-207.

21. Herwana E, Setiabudy R, Soegondo S, et al. Soy isoflavone supplementation increases equolproducing capability in postmenopausal women with osteopenia. Univ Med 2012;31:120-30.

22. Chilibeck PD, Vatanparast H, Pierson R, et al. Effect of training combined with isoflavone supplementation on bone and lipids in postmenopausal women: A randomized clinical trial. J Bone Min Res 2013;28:780-93. Doi: 10.1002/ jbmr.1815.

23. EFSA Panel on Dietetic Products, Nutrition and Allergies (NDA); Scientific opinion on the substantiation of health claims related to soy isoflavones and maintenance of bone mineral density (ID 1655) and reduction of vasomotor symptoms associated with menopause. EFSA J 2012;10:2847. doi:10.2903/j.efsa.2012.2847.

24. Messina M. Soy and health update: Evaluation on the clinical and epidemiologic literature. Nutrients 2016;8:754. 42 pages. Doi: 10.3390/ nu8120754. 